\title{
Characterization of silicon nitride thin films deposited by hot- wireCVD at low gas flow rates
}

Clive J. Oliphant, Christopher J. Arendse, Theophillus F.G. Muller and Dirk Knoesen

\begin{abstract}
We examined the chemical, structural, mechanical and optical properties of amorphous hydrogenated silicon nitride thin films deposited by hot-wire chemical vapour deposition using $\mathrm{SiH}_{4}, \mathrm{NH}_{3}$ and $\mathrm{H}_{2}$ gases at total flow rates below $33 \mathrm{sccm}$. Time of flight secondary ion mass spectroscopy reveal that the film surfaces consist of predominantly $\mathrm{Si}$ with hydrogenated $\mathrm{Si} x \mathrm{~N} y \mathrm{O}_{z}$ species. Energy dispersive X-ray spectroscopy and X-ray photoelectron spectroscopy corroborate on the N/Si ratio. Electron energy loss spectroscopy discloses that the thickness of the nitrogen rich oxidized interface between the $\mathrm{SiN} x$ films and the c-Si substrate decrease with an enhancing $\mathrm{NH}_{3}$ flow rate. By varying the $\mathrm{NH}_{3}$ flow rate, dense $\mathrm{SiN} x$ films can be realized with hydrogen content between 16 and 9 at.\%, a refractive index between 3.5 and 1.9 and optical band gap ranging from 2 to $4.5 \mathrm{eV}$. The $\operatorname{SiN} x$ film stress is compressive for $\mathrm{N} / \mathrm{Si}<0.4$ and tensile for higher $\mathrm{N} / \mathrm{Si}>0.55$. Mechanisms relating the HWCVD conditions and the film structure and properties are proposed.
\end{abstract}

\section{Introduction}

Silicon nitride $(\operatorname{SiN} x)$ is an important dielectric that enjoyed active research interest during the last few decades. $\mathrm{SiN} x$ has been applied as surface and bulk passivation layers for solar cells [1], thin film transistors [2], antireflection coatings [3] and has shown promise as a light emitting material [4]. The wide application scope of $\operatorname{SiN} x$ can be attributed to its refractive index, optical band gap, structural properties and molecular composition; all of which can be tuned by varying the deposition conditions $[1,5,6]$.

Plasma enhanced chemical vapour deposition (PECVD) is the conventional synthesis technique for manufacturing $\mathrm{SiN}_{x}$ thin films. An alternative technique for the synthesis of $\operatorname{SiN} x$ is hot-wire chemical vapour deposition (HWCVD). Compared to PECVD, $\operatorname{SiN} x$ synthesized by HWCVD experience no ion bombardment and can be deposited at higher deposition rates [7] with reduced hydrogen content [8]. Despite the numerous studies on the synthesis of $\mathrm{SiN} x$ from $\mathrm{SiH}_{4}$ and $\mathrm{NH}_{3}$ gas mixtures, reports on the effect of the addition of $\mathrm{H}_{2}$ to the process gasses on the structure-property relationship 
of $\mathrm{SiN} x$ thin films has received less attention [9-11]. The benefits of adding $\mathrm{H}_{2}$ to the usual $\mathrm{NH}_{3} / \mathrm{SiH}_{4}$ gas mixture include an enhanced incorporation of $\mathrm{N}$ into the thin film, reduced $\mathrm{NH}_{3}$ flow rates down to $5 \mathrm{sccm}$ and film conformity on the substrate [911]. In most cases, the filament temperature during the HWCVD of $\mathrm{SiN} x$ films were $>1700{ }^{\circ} \mathrm{C}[1-3,5,7-12]$, which can lead to filament metal impurities incorporated into the films $[10,13]$.

In this study, we employ HWCVD to deposit transparent, low reflection, dense amorphous $\mathrm{SiN} x$ thin films from a $\mathrm{SiH}_{4} / \mathrm{NH}_{3} / \mathrm{H}_{2}$ gas mixture at a substrate temperature of $240{ }^{\circ} \mathrm{C}$ and a filament temperature of $\sim 1600{ }^{\circ} \mathrm{C}$. The total gas flow rate ranged from 30 to $33 \mathrm{sccm}$ with that of $\mathrm{NH}_{3}$ varied from 1 to $3 \mathrm{sccm}$, which is substantially lower than the usually deposition regime for $\operatorname{SiN} x$. In addition, we compare the N/Si compositional characterization of $\mathrm{SiN} x$ thin films as probed by energy dispersive X-ray spectroscopy (EDS) and X-ray photoelectron spectroscopy (XPS). The internal structure and elemental distribution was investigated using highresolution transmission electron microscopy (HR-TEM) and electron energy loss spectroscopy (EELS). We then propose a relationship between the HWCVD conditions, film structure, mechanical and optical properties.

\section{Experimental procedure \\ 2.1 Deposition conditions}

SiN $x$ thin films were deposited simultaneously on Corning ${ }^{\circledR} 7059$ and $\mathrm{Si}\left(\begin{array}{lll}1 & \text { o } & 0\end{array}\right)$ substrates using a high vacuum MVSystems HWCVD system described elsewhere [14]. The deposition time, substrate temperature, deposition pressure, filament temperature, silane flow rate and hydrogen flow rate were fixed at $60 \mathrm{~min}, 240{ }^{\circ} \mathrm{C}, 150$ $\mu$ bar, $1600{ }^{\circ} \mathrm{C}$, $2 \mathrm{sccm}$ and $28 \mathrm{sccm}$, respectively. The $\mathrm{NH}_{3}$ flow rate was varied from 1 to $3 \mathrm{sccm}$ (in increments of $0.5 \mathrm{sccm}$ ).

\subsection{Thin film characterization}

The elemental composition of the SiN $x$ thin films were determined using XPS and EDS. XPS was performed in wide and narrow scan modes on a PHI ${ }^{\circledR}$ Quanta 2000 spectrometer using monochromatic AlKcx X-rays. EDS analysis was performed at $6 \mathrm{kV}$ using a pure $\mathrm{Si}$ standard as the quantification optimization element in an OXFORD INCA EDS system in a Zeiss LEO 1525 field emission gun scanning electron microscope (FEGSEM). The bonding configuration of the $\operatorname{SiN} x$ thin films were investigated using a PerkinElmer Spectrum 100 fast-Fourier transformed infrared (FTIR). The spectra were collected in transmission geometry from 400 to $4000 \mathrm{~cm}^{-1}$ with a spectral resolution of $1 \mathrm{~cm}^{-1}$. The FTIR spectra were corrected for coherent and incoherent reflections $[15,16]$. The total hydrogen content in the film was determined using elastic recoil detection (ERD) analysis. The ERD analysis was conducted using a $3 \mathrm{MeV}$ mono-energetic and collimated beam of $4 \mathrm{He}^{+}$ions 
accelerated by the van de Graaff accelerator at iThemba Labs, in Cape Town, South Africa. The recoiled atoms were detected at an angle of $30^{\circ}$ with respect to the incident ion beam. A Kapton reference material (coated with $\sim 1 \mathrm{~A}^{\circ} \mathrm{Pt}$ ) was used for energy and geometry calibration. The total $\mathrm{H}$ content was calculated from the ERD spectra using the SIMNRA simulation software.

Time of flight (ToF-SIMS) spectra of the $\mathrm{SiN} x$ film surface were acquired using a TOF.SIMS5 system equipped with a $\mathrm{Bi}_{1}{ }^{++}$liquid metal ion source. Positive and negative ion spectra were accumulated with a pulsed beam current of $1 \mathrm{nA}$ at $20 \mathrm{kV}$. Spectra were calibrated with hydrocarbons. The mass resolution was typically above 10,000. Raman spectra were recorded in backscattering geometry in the region 100$1300 \mathrm{~cm}^{-1}$ with a spectral resolution of $0.4 \mathrm{~cm}^{-1}$, using a Jobin-Yvon HR8oo microRaman spectrometer operated at an excitation wavelength of $514.5 \mathrm{~nm}$. The power of the Raman laser was kept below $5 \mathrm{~mW}$ to avoid laser induced crystallization.

Cross-sections of the SiN $x$ films were prepared by a FEI Helios NanoLab 650 Dual Beam focussed-ion beam SEM (FIBSEM). Subsequently, high-resolution transmission electron microscopy (HRTEM) was performed on the cross-sections using a JEOL ARM 200F TEM. Electron energy loss spectroscopy (EELS) was performed in scanning transmission electron microscopy (STEM) mode at a step size of $4 \mathrm{~nm} \times 4 \mathrm{~nm}$ to acquire $\mathrm{Si}, \mathrm{N}$ and $\mathrm{O}$ elemental maps. The Gatan Quantum GIF energy filter was used to perform the EELS maps at a collection angle of 41.7 mrad. Electron diffraction was performed on a FEI Tecnai F2O FEGTEM at $200 \mathrm{kV}$. The film stress was estimated from curvature measurements determined on Corning (thermal expansion $4.6 \mu /{ }^{\circ} \mathrm{C}$, Young's modulus 67.6 GPs and Poisson's ratio 0.28) substrates before and after deposition a using a Taylor stylus profilometer. The total film stress was then determined using Stoney's equation [17]. However, the total film tress is equal to sum of the intrinsic stress and the thermal stress. The thermal stress was determined from the constants for a-Si in [18] (thermal expansion coefficient $1 \mu /{ }^{\circ} \mathrm{C}$, Young's modulus $130 \mathrm{GPa}$ and Poison's ratio 0.28$)$.

Optical transmission and reflection spectra were measured using a CARY $1 \mathrm{E}$ UV/VIS spectrophotometer in the range $200-900 \mathrm{~nm}$ with a spectral resolution of $1 \mathrm{~nm}$. The refractive index, absorption coefficients and optical thickness were calculated by employing the Bruggeman effective medium approximation (BEMA) model [19]. 


\section{Results and discussion}

\subsection{Film growth rate}

Fig. 1 shows that the film growth rate increases as a function of $\mathrm{NH}_{3}$ flow rate $\left({ }^{\circ} \mathrm{NH}_{3}\right)$. The maximum growth rates are competitive to that reported for PECVD $[8,20]$ and also for some HWCVD studies [20]. However, the growth rates are still promising considering that we used a lower deposition pressure, filament temperature of $1600{ }^{\circ} \mathrm{C}$ and total gas flow rates lower by a factor of $\sim 12$ compared to that used in [7].

The HWCVD process of $\mathrm{SiN} x$ is complex and can be divided into three stages, namely the dissociation of the $\mathrm{NH}_{3}, \mathrm{SiH}_{4}$ and $\mathrm{H}_{2}$ gases at the filament, gas phase reactions and finally surface reactions at the substrate. During the gas dissociations at the heated Ta-filament; $\mathrm{Si}, \mathrm{N}$ and $\mathrm{H}$ containing radicals are created, which can then proceed to the other two growth stages. However, filament degradation studies showed that the radicals diffuse within the Ta-filament; consequently resulting in the formation of Tanitrides and silicides. This depletion of growth species from the ambient can initially lead to inferior growth rates, especially in this study where the depositions were started with a pure Ta-filament surface. Afterwards, the silicide layer encapsulating the filament becomes thicker, which reduces the diffusion of radicals within the filament, i.e. more radicals are now available for the deposition leading to the higher growth rates at higher $\mathrm{NH}_{3}$ flow rates.

Gas phase reactions are also a contributing factor to the film growth rate. The probability for a gas molecule to be dissociated by the heated filament surface is inversely proportional to the pressure and directly proportional to the square root of the filament temperature [21,22]. It is therefore possible that not all $\mathrm{SiH}_{4}$ molecules are dissociated at our deposition conditions; given the deposition pressure of 150 $\mu$ bar and low filament temperature of $1600{ }^{\circ} \mathrm{C}$. However, the $\mathrm{NH}_{3}$ partial pressure enhances with an increasing $\mathrm{NH}_{3}$ gas flow rate. Coupled with the high $\mathrm{H}_{2}$ concentration and the effectiveness of a heated filament to dissociate $\mathrm{H}_{2}$ [23], there is expected to be a high concentration of atomic hydrogen during the deposition. Atomic hydrogen is unstable and can dissociate those $\mathrm{SiH}_{4}$ molecules that were not dissociated by the heated filament [24]. Consequently an increase in growth rate occurs at higher $\mathrm{NH}_{3}$ flow rates. 


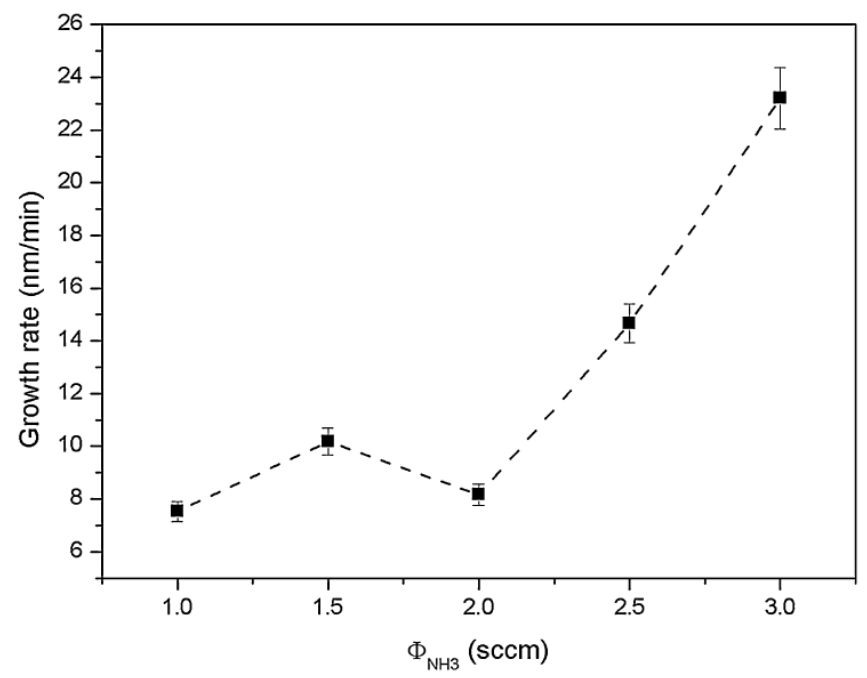

Fig. 1. Film growth rate at various $\mathrm{NH}_{3}$ flow rates.

\subsection{Compositional properties}

Fig. 2 reveals that the hydrogen concentration, determined from ERD, decrease monotonically from $\sim 16$ at.\% to $\sim 9$ at.\% with an increase in ${ }^{\circ} \mathrm{NH}_{3}$. Fig. 3 shows deconvoluted XPS spectra of the $\mathrm{Si} 2 \mathrm{p}$ orbital for $\mathrm{SiN} x$ thin films deposited at various ${ }^{\circ} \mathrm{NH}_{3}$. The spectra can be deconvoluted into three Gaussian peaks with centres at $\sim 99.4 \mathrm{eV}$ ( $\mathrm{Si} \mathrm{Si}$ ), $103 \mathrm{eV}$ ( $\mathrm{Si} \mathrm{O}$ ) and $100.1 \mathrm{eV}$ ( $\mathrm{Si}$ N). The presence of the Si O peak indicates that the surface is oxidized. In addition, the simultaneous presence of $\mathrm{Si} \mathrm{Si}$ and $\mathrm{Si} \mathrm{N}$ reveal that the films are dual phase, i.e. the films are composed of a mixture of $\mathrm{Si} \mathrm{Si}$ and $\mathrm{Si} \mathrm{N}$ networks. Fig. 4a presents the relationship between the $\mathrm{Si} \mathrm{N}$ area percentage (relative to $\mathrm{Si} \mathrm{O}$ and $\mathrm{Si} \mathrm{Si}$ ) as a function of ${ }^{\circ} \mathrm{NH}_{3}$ flow rate. The concentration of the $\mathrm{Si} \mathrm{N}$ bonds grows linearly with increasing $\mathrm{NH}_{3}$ flow rate at the expense of the Si Si bonds, indicating an efficient use of the supply gases. This phenomenon has been observed before and was attributed to the gas phase dissociation of $\mathrm{NH}_{3}$ by atomic hydrogen [9]. Fig. $4 \mathrm{~b}$ shows an XPS depth profile for the sample deposited at ${ }^{\circ} \mathrm{NH}_{3}=3 \mathrm{sccm}$. The depth profile reveals that $\mathrm{O}$ and $\mathrm{C}$ are confined to the surface while homogenous atomic concentrations of $\mathrm{N}$ and $\mathrm{Si}$ constitute the bulk of the film.

The N/Si atomic ratio $(x)$ is the most important factor that governs the electrical and optical properties of $\mathrm{SiN} x$. In general, the $\mathrm{N} / \mathrm{Si}$ ratio is determined from Rutherford backscatter spectroscopy (RBS), heavy ion elastic recoil detection (ERD) [7], FTIR [9] or indirectly from the film refractive index [25]. However, the proportionality constants necessary for quantification from FTIR varies with film composition [26]; and the refractive index is influenced by the film density which, in turn, may also depend on the deposition technique [27]. Currently, scanning electron microscopes (SEM) are becoming increasingly accessible and coupled to a SEM in most cases is an energy dispersive X-ray spectroscopy (EDS) detector. EDS is used to identify and quantify elemental compositions of various elements with an atomic 
number larger than 4 (Be). Despite its immense development for determining elemental compositions of bulk materials, EDS on thin films within the SEM have received less attention. This can be attributed to the beam penetration depth, issues relating to the homogeneity of the thin film (which will influence the quantification) and relatively high inaccuracies for low atomic number elements such as $\mathrm{C}$. Nevertheless, with the advent of more sensitive detectors and enhanced detection levels at low acceleration voltages, EDS may be used as an alternative option to determine the elemental composition of $\operatorname{SiN} x$ thin films.

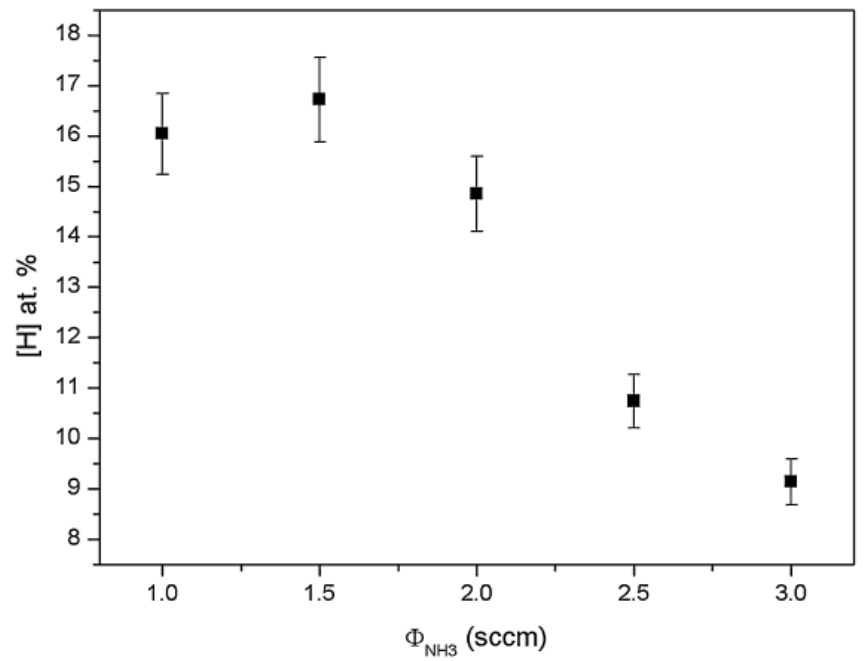

Fig. 2. Total hydrogen content as a function of $\Phi_{\mathrm{NH}_{3}}$.
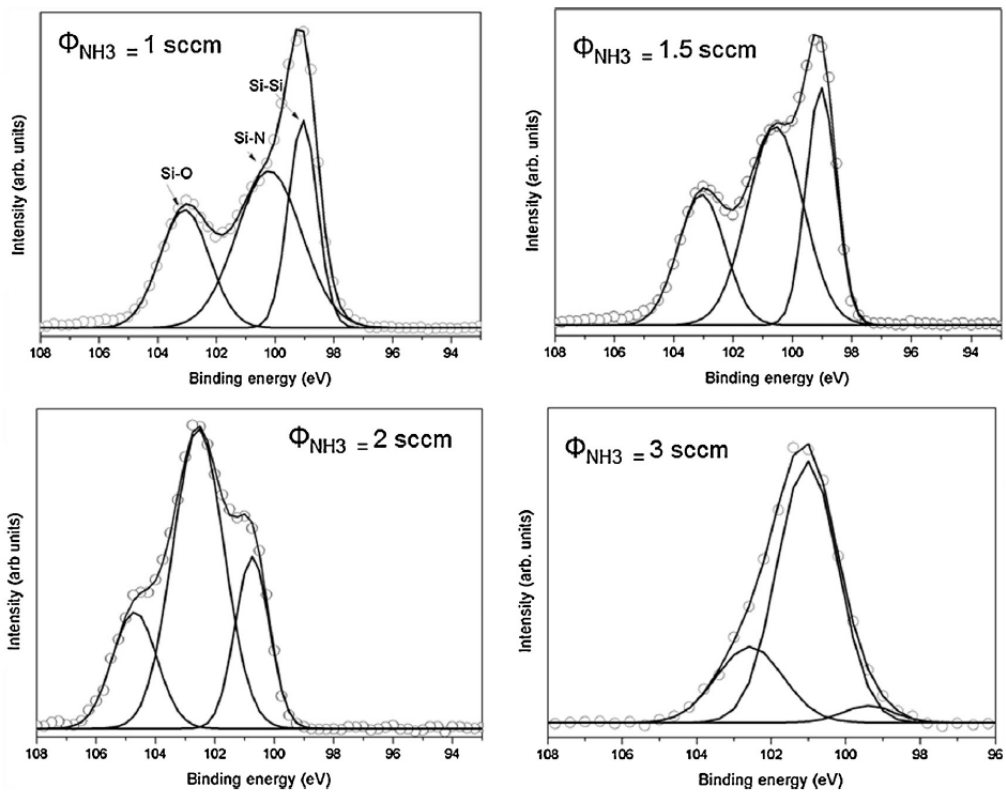

Fig. 3. XPS spectra of Si 2 p level for $\mathrm{SiN}_{\mathrm{x}}$ films deposited at various $\Phi_{\mathrm{NH}_{3}}$. 

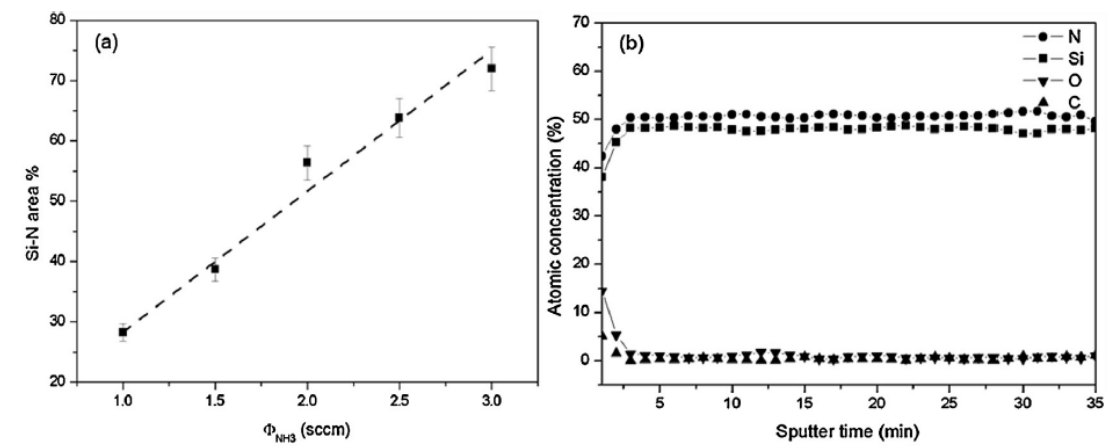

Fig. 4. (a) Si-N area percentage (with linear fit) at various $\mathrm{NH}_{3}$ flow rates and (b) XPS elemental depth profile of the sample deposited at $\Phi_{\mathrm{NH}_{3}}=3 \mathrm{sccm}$.

Table 1

Comparison between XPS and EDS. The values are within 5 at. \% standard deviation. The total hydrogen content [H] was determined from ERD.

\begin{tabular}{|c|c|c|c|c|c|c|c|}
\hline$\Phi_{\mathrm{NH}_{3}}(\mathrm{sccm})$ & [N] XPS(at.\%) & {$[\mathrm{N}]_{\text {EDS }}($ at.\%) } & [Si] XPS(at.\%) & [Si $]_{\operatorname{EDS}}$ (at.\%) & {$[\mathrm{H}]$ (at.\%) } & $x_{\text {XPS }}$ & $x_{\mathrm{EDS}}$ \\
\hline 1 & 15.66 & 18.65 & 68.30 & 65.31 & 16.04 & 0.23 & 0.29 \\
\hline 1.5 & 20.90 & 22.33 & 62.38 & 60.95 & 16.72 & 0.34 & 0.37 \\
\hline 2 & 30.72 & 31.02 & 54.43 & 54.13 & 14.85 & 0.56 & 0.57 \\
\hline 3 & 47.01 & 49.27 & 43.85 & 41.59 & 9.14 & 1.07 & 1.18 \\
\hline
\end{tabular}

Presented in Table 1 is a comparison between the $\mathrm{N}$ and $\mathrm{Si}$ atomic percentages determined from XPS and EDS; showing the good correlation between these two independent techniques. The values are adjusted to include the $\mathrm{H}$-content determined from ERD.

FTIR is the preferred technique used to determine and quantify the bonding configurations of $\mathrm{SiN}_{\mathrm{X}}$ thin films. Fig. 5 shows a typical FTIR spectrum of a $\mathrm{SiN}_{\mathbf{X}}$ sample revealing the presence of four peaks: the Si N (stretching) mode near $850 \mathrm{~cm}^{-1}$, $\mathrm{N} \mathrm{H}$ bending mode at $1200 \mathrm{~cm}^{-1}$, the $\mathrm{Si} \mathrm{H}$ stretching mode near $2190 \mathrm{~cm}^{-1}$ and the $\mathrm{N}$ $\mathrm{H}$ stretching mode at $3330 \mathrm{~cm}^{-1}$ [26]. The amounts of the Si N, N H and Si H bonds can be obtained from the relevant infrared absorption bands by:

$$
[X-Y]=A_{X-Y} \int \frac{\alpha(\omega)}{\omega}
$$

where ، $(\omega)$ is the absorption coefficient at wavenumber $\omega$ and $\mathrm{AX}-\mathrm{Y}$ is the proportionality coefficient. 


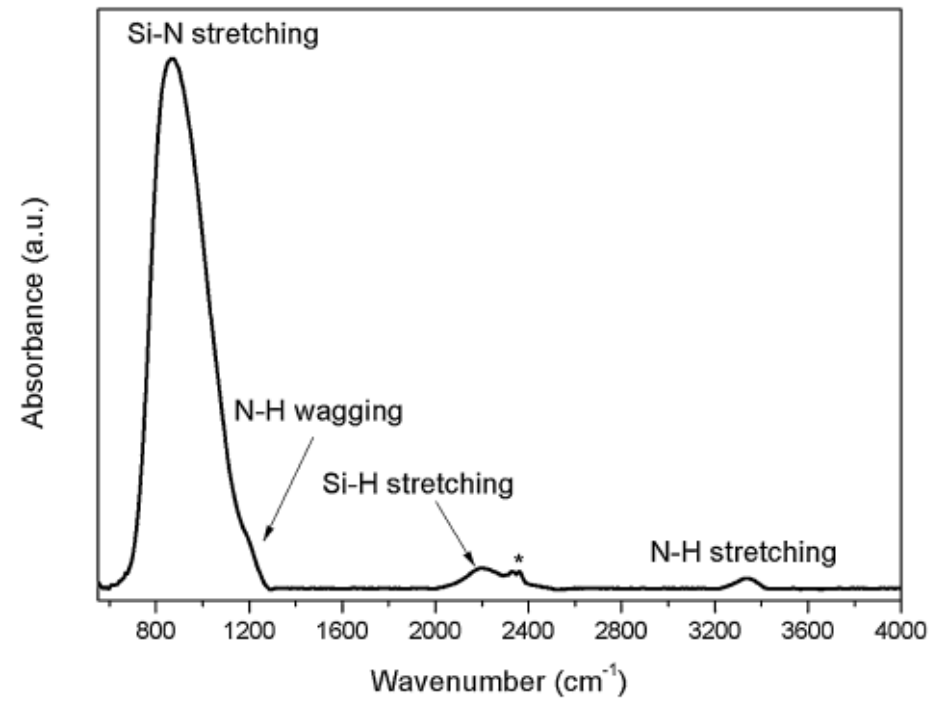

Fig. 5. Typical FTIR spectrum of the sample deposited at $3 \mathrm{sccm} \mathrm{NH}$. The peaks indicated by ${ }^{*}$ correspond to fluctuations in the $\mathrm{CO}_{2}$ concentrations within the spectrometer which were consequently not properly removed by the background.

The proportionality coefficients proposed by Lanford and Rand [28] for the $\mathrm{N} \mathrm{H}$ and $\mathrm{Si} \mathrm{H}$ bond concentrations were used. For the $[\mathrm{Si} \mathrm{N}]$ the average value of $1.4 \times 10^{19}$ $\mathrm{cm}^{-2}$ was chosen as proposed by Verlaan et al. [5]. Then, assuming the absence of $\mathrm{H}$ $\mathrm{H}$ and $\mathrm{N} \mathrm{N}$ bonds in the thin films [5,25,29], the atom concentrations of $\mathrm{H}, \mathrm{N}$ and $\mathrm{Si}$ can be determined by the following set of equations [30]:

$$
\begin{aligned}
& {[\mathrm{H}]=[\mathrm{Si}-\mathrm{H}]+[\mathrm{N}-\mathrm{H}]} \\
& {[\mathrm{N}]=\frac{[\mathrm{Si}-\mathrm{N}]+[\mathrm{N}-\mathrm{H}]}{3}} \\
& {[\mathrm{Si}]=\frac{[\mathrm{Si}-\mathrm{N}]+[\mathrm{Si}-\mathrm{H}]}{4}+\frac{[\mathrm{Si}-\mathrm{Si}]}{2}}
\end{aligned}
$$

The [Si-Si] bond density can be derived from Eq. (4) and $[\mathrm{Si}]=[\mathrm{N}] / x$ as:

$$
[\mathrm{Si}-\mathrm{Si}]=2 \frac{[\mathrm{N}]}{x}-\frac{[\mathrm{Si}-\mathrm{N}]+[\mathrm{N}-\mathrm{H}]}{2}
$$

Fig. 6 presents the FTIR atomic concentrations of [H], [N], [Si] and [Si Si]. A relatively higher concentration of $[\mathrm{Si} \mathrm{Si}]$, $[\mathrm{Si}]$ and $[\mathrm{H}]$ exist at $\mathrm{N} / \mathrm{Si} \leq 0.30$, which then decrease with an increasing $\mathrm{N} / \mathrm{Si}$ ratio. Initially, the $[\mathrm{N}]$ atomic concentration is in inferior amounts, which then gradually increase with an increasing $\mathrm{N} / \mathrm{Si}$ ratio. The values of the atomic concentrations are relatively inferior compared to that reported for $\mathrm{SiN}_{\mathrm{X}}$ films deposited from $\mathrm{SiH}_{4}$ and $\mathrm{NH}_{3}$ mixtures [5,30] (the studies used the same proportionality factors), which indicates an increase in defects as the $\mathrm{NH}_{3}$ flow rate increases. The peak position of 
the $\mathrm{Si} \mathrm{H}$ bond is influenced by the composition of the $\mathrm{SiN}_{\mathrm{X}}$ films [7] and more specifically, the different types of back bonding of the hydrogenated Si atom [25]. Fig. 6b reveals that the peak position of $\mathrm{S} \mathrm{H}$ scales linearly with $\mathrm{N} / \mathrm{Si}$. The absence of $\mathrm{NH}_{3}$ from the gas mixture in this study will result in the deposition of microcrystalline silicon instead of amorphous silicon, due to the high $\mathrm{H}_{2}$ dilution used in this study, which favours the crystallization of silicon [31]. The $\mathrm{Si} H$ peak position at $2092 \mathrm{~cm}^{-1}(\mathrm{~N} / \mathrm{Si}=0)$ falls within the range expected for microcrystalline silicon [32] and is close to $2220 \mathrm{~cm}^{-1}$ for N/Si $\sim 1.33$ corresponding to a-Si3 $\mathrm{N}_{4}[1]$.
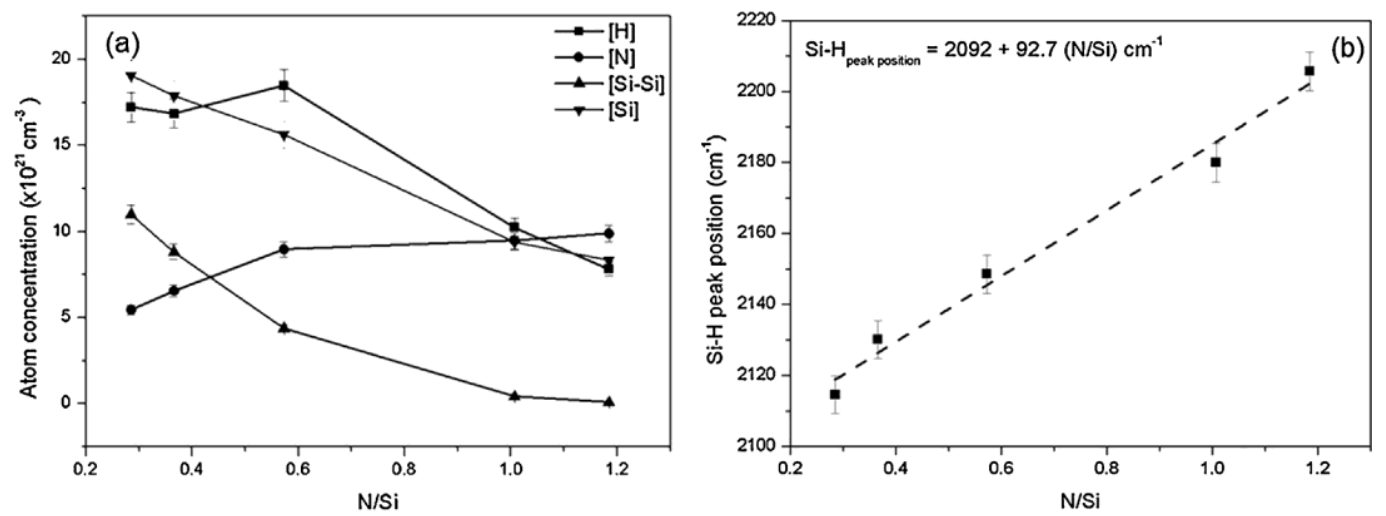

Fig. 6. (a) FTIR atomic concentrations and (b) variation of the $\mathrm{Si} H$ peak position as a function of N/Si.

ToF-SIMS is a sensitive analytical technique that is useful to interrogate the chemical structure and composition of surfaces. However, the application of ToF-SIMS for characterizing $\operatorname{SiN} x$ thin films synthesized by HWCVD is quite rare [33]. In this study, ToFSIMS was used to determine if metal impurities from the filament were incorporated into the film and whether the surface composition followed trends seen in FTIR, ERD, XPS and EDS. Fig. 7 presents positive ion ToF-SIMS spectra of $\mathrm{SiN} x$ films with various N/Si ratios. The most intense peak is the $\mathrm{Si}^{+}$peak at $27.99 \mathrm{~m} / \mathrm{z}$, against which the spectra was normalized. The most dominating $\mathrm{Si} \mathrm{H}$ signal is the $\mathrm{SiH}^{+}$peak centred at $28.98 \mathrm{~m} / \mathrm{z}$, with fewer contributions from $\mathrm{SiH}_{2}$ and $\mathrm{SiH}_{3}$. The most intense $\mathrm{Si} \mathrm{N}$ based signal is the $\mathrm{SiNH}_{2}{ }^{+}$peak at $44 \mathrm{~m} / z$. Other noteworthy peaks are related to various hydrocarbons and oxides. The presence of $\mathrm{C}$ and $\mathrm{O}$ signals indicate contaminated oxidized surfaces, corroborating the XPS analysis. No heavy metal based ( $\mathrm{Ta}$ ) peaks were observed, indicating no contamination from the filament or at most below the ToF-SIMS detection limit. Negative ion spectra (not shown here) contained similar peaks, although $\mathrm{H}$ was the most intense peak.

Fig. $7 \mathrm{~b}$ and $\mathrm{c}$ shows that the relative intensity of the $\mathrm{SiH}$ and the $\mathrm{H}$ signal decreases with an enhancing N/Si ratio, correlating to the trends shown by the FTIR and ERD analysis. The trends in the relative intensities of the $\mathrm{SiNH}_{2}{ }^{+}$and oxides (not shown here) was irregular with an enhancing $\mathrm{NH}_{3}$ flow rate. 
An increase in the $\mathrm{NH}_{3}$ flow rate results in an enhancement in the incorporation of $\mathrm{N}$ into the film. The Si N and Si H bonds are more energetically favoured than Si Si bonds [34]. Consequently, the $\mathrm{Si} \mathrm{Si}$ bonding decreases at the expense of the $\mathrm{Si} \mathrm{N}$ bonds as the $\mathrm{N}$ content within the film enhances.
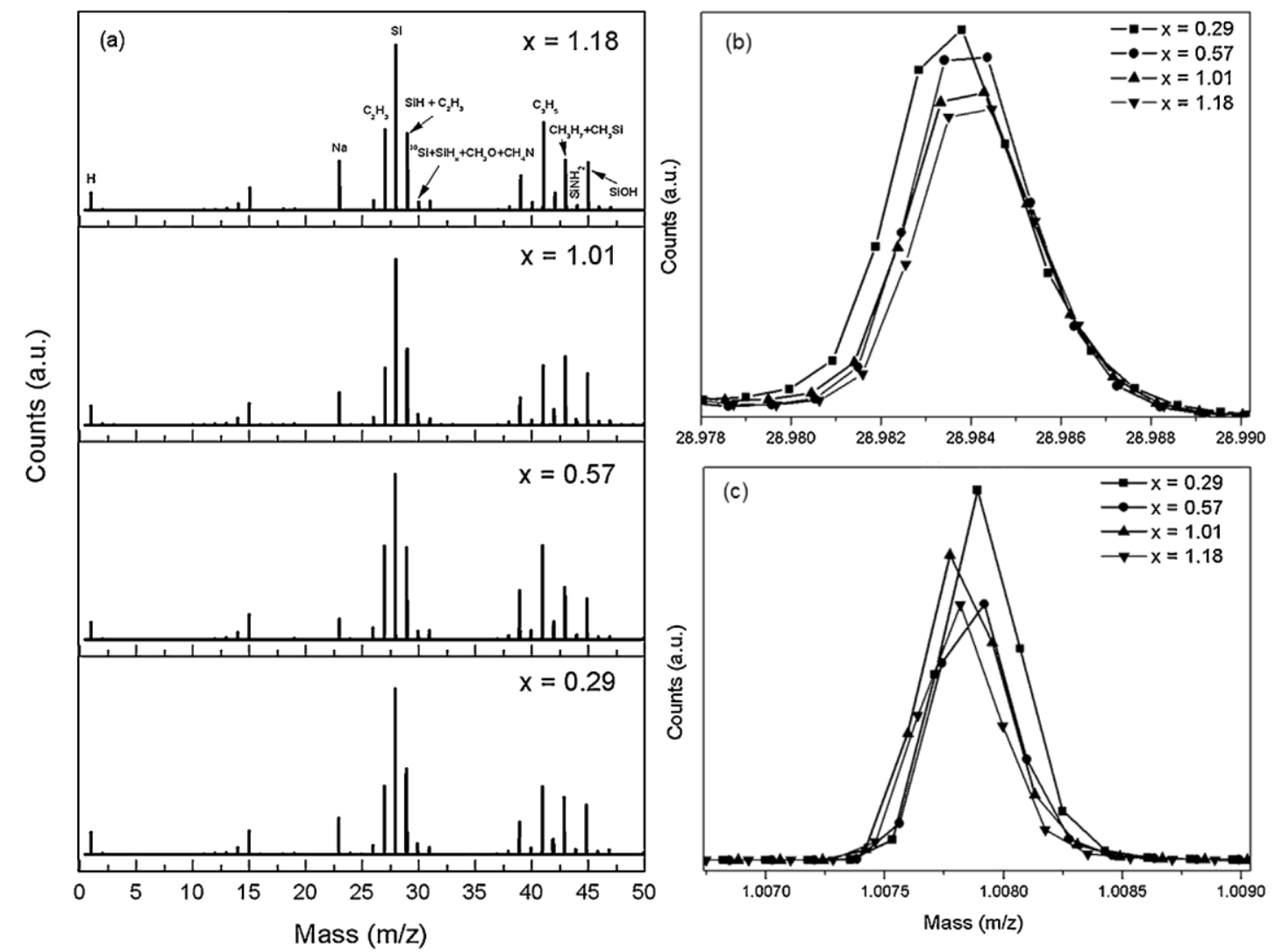

Fig. 7. (a) Normalized ToF-SIMS spectra (positive mode) of the $\mathrm{SiN}_{\mathrm{X}}$ surface, (b) $\mathrm{SiH}$ and (c) $\mathrm{H}$ signals at various N/Si ratios.
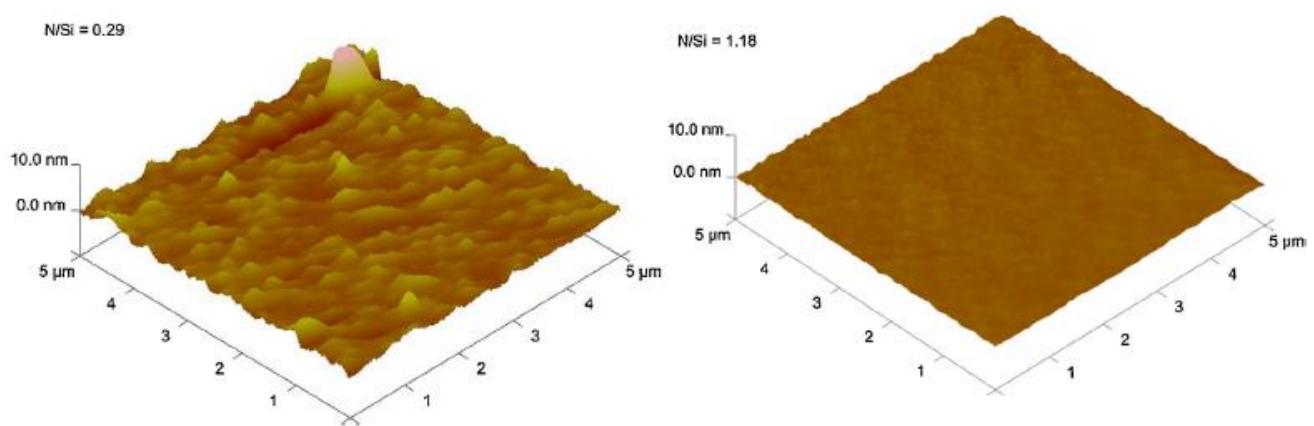

Fig. 8. 3D AFM micrographs of the $\operatorname{SiN}_{x}$ films at different $\mathrm{N} / \mathrm{Si}$ ratios.

However, the number of $\mathrm{Si} \mathrm{H}$ bonds and $\mathrm{H}$ concentration decreased at higher $\mathrm{NH}_{3}$ flow rates. Verlaan et al. [35] observed similar trends and attributed the decreasing Si $\mathrm{H}$ and $\mathrm{H}$-concentration to cross-linking reactions within the film, i.e. the formation of $\mathrm{Si}$ $\mathrm{N}$ and $\mathrm{H}_{2}$ (released as gas [36]) bonds via the reactions of $\mathrm{N} \mathrm{H}$ with $\mathrm{Si} \mathrm{H}$ bonds. 


\subsection{Film microstructure}

The surface roughness of $\operatorname{SiN} x$ thin films is an important parameter to be considered in thin film transistors and anti-reflective coatings for solar cells. Fig. 8 shows representative $3 \mathrm{D}$ AFM images of $\mathrm{SiN} x$ thin films with varying $\mathrm{N}$-content. The rootmean-square (RMS) roughness values shown in Fig. 9 reveals that the surface roughness decreases to a minimum value of $\sim 0.15 \mathrm{~nm}$, substantially lower than that reported for HWCVD of $\mathrm{SiN} x$ using a $\mathrm{SiH}_{4}$ and $\mathrm{NH}_{3}$ mixture [37].

Atomic hydrogen is released as a by-product during the decomposition of $\mathrm{NH}_{3}$ [38]. Therefore, an increased $\mathrm{NH}_{3}$ flow rate leads to an increasing atomic hydrogen concentration. The subsequent high concentration of atomic hydrogen can then result in an improved $\mathrm{H}$-terminated surface, thereby promoting the diffusion of radicals on the surface, which can lead to smoother surfaces [39]. The internal structure of the $\mathrm{SiN} x$ thin films were investigated by TEM and EELS. Fig. 10 shows TEM micrographs of the $\operatorname{SiN} x$ films at $x=0.29$ and $x=1.18$. The films are amorphous as indicated by electron diffraction patterns (insets in Fig. 10) and are dense, which is suitable for device applications. The film thickness increased with an increasing $\mathrm{NH}_{3}$ flow rate, confirming the UV-vis and profilometer measurements. Fig. 11 presents EELS elemental maps of Si, N and O. Despite the thickness of the cross-sections being less than at most half the inelastic electron mean free path at $200 \mathrm{kV}$, the EELS maps are qualitative in that it was not possible in the current TEM set-up to monitor the intensity and position of the zero-loss peak while acquiring the elemental maps. Nevertheless, valuable qualitative information about the $\mathrm{Si}, \mathrm{N}$ and $\mathrm{O}$ profiles within the $\operatorname{SiN} x$ can be extracted from EELS.

The O-signal is intense at the $\mathrm{SiN} x / \mathrm{c}-\mathrm{Si}$ substrate interface and at the $\mathrm{SiN} x$ surface. The presence of an oxide between the $\operatorname{SiN} x$ and the substrate indicates that the HF dip was not effective in removing the native oxide from the c-Si substrate. Confirming the XPS and ToF-SIMS findings are surface oxide layers on the $\operatorname{SiN} x$ films. However, oxidation subsequent to the FIB sample preparation also occurs and contributes to the O-signal throughout the $\mathrm{SiN} x / \mathrm{c}-\mathrm{Si}$ cross-sections as revealed by the similar O-signal intensities at the C-coating, $\mathrm{SiN} x$ film bulk and the c-Si substrate.

The intensity of the EELS N-signal is homogenous throughout the $\operatorname{SiN} x$ films and enhances relative to the $\mathrm{Si}$-signal with an increasing N/Si ratio; indicating an enriching N-content within the films, which supports the XPS, EDS and FTIR analysis. Furthermore, there are regions within the $\mathrm{N}$ - and Si-signals that have different brightness; indicating nanosized regions with $\mathrm{Si}$ - and/or N-rich areas. Interestingly, a nitrogen rich silicon oxide interface resides between the $\mathrm{SiN} x$ and c-Si substrate. The thickness of the silicon oxynitride layer decreased from $\sim 30 \mathrm{~nm}$ to $10 \mathrm{~nm}$ as the $\mathrm{NH}_{3}$ flow rate increases from 1 to $3 \mathrm{sccm}$. 
XRD analysis (not shown here) confirmed the absence of crystallinity from the deposited SiNx thin films. Raman spectroscopy is a powerful tool for probing the structure of Si based thin films. Fig. 12 presents the Raman spectra for samples with different $\mathrm{N} / \mathrm{Si}$ ratios. The dual phase nature of the films is clear through the simultaneous presence of a-Si transverse optic (TO) peak at $\sim 480 \mathrm{~cm}^{-1}$ with the 2nd order TO peak at $\sim 930 \mathrm{~cm}^{-1}$ and $\mathrm{SiN} x$ peaks at $\sim 800 \mathrm{~cm}^{-1}[40,41]$. Samples with a higher N/Si ratio displayed additional $\mathrm{SiN} x$ peaks at $700 \mathrm{~cm}^{-1}$ and $1150 \mathrm{~cm}^{-1}$ [41]. The absence of the c-Si TO peak at $\sim 515 \mathrm{~cm}^{-1}$ indicates that there is no detectable crystallinity [42], confirming the TEM and XRD analysis. The Raman spectra were deconvoluted into Gaussian peaks corresponding to a-Si and $\mathrm{SiN} x$ as shown in Fig. 13. Fig. 14 shows the integrated intensity ratio of the $\mathrm{SiN} x$ and a-Si TO peaks $\left(I_{\mathrm{SiN}} x / I_{\mathrm{a}-\mathrm{Si}}\right)$, revealing that it increases with an increasing $\mathrm{N} / \mathrm{Si}$ ratio, which is indicative of an increasing fraction of $\operatorname{SiN} x$, corroborating the XPS and FTIR results. The full width at half maximum (FWHM) of the a-Si TO peak increases with an enhancing N/Si ratio, whereas the FWHM of the $\mathrm{SiN} x$ peak increases until N/Si $\sim 0.6$ and then decreases at higher $\mathrm{N}$ values. This can be interpreted as the ordering within the a-Si network is relatively enhanced within $\mathrm{Si}$-rich $\mathrm{SiN} x$ films.

Fig. 15 presents the integrated intensity ratio $17=I_{2} \mathrm{To} / I \mathrm{TO}$ of a-Si; disclosing that it increases monotonically with an increasing $\mathrm{N} / \mathrm{Si}$ ratio.

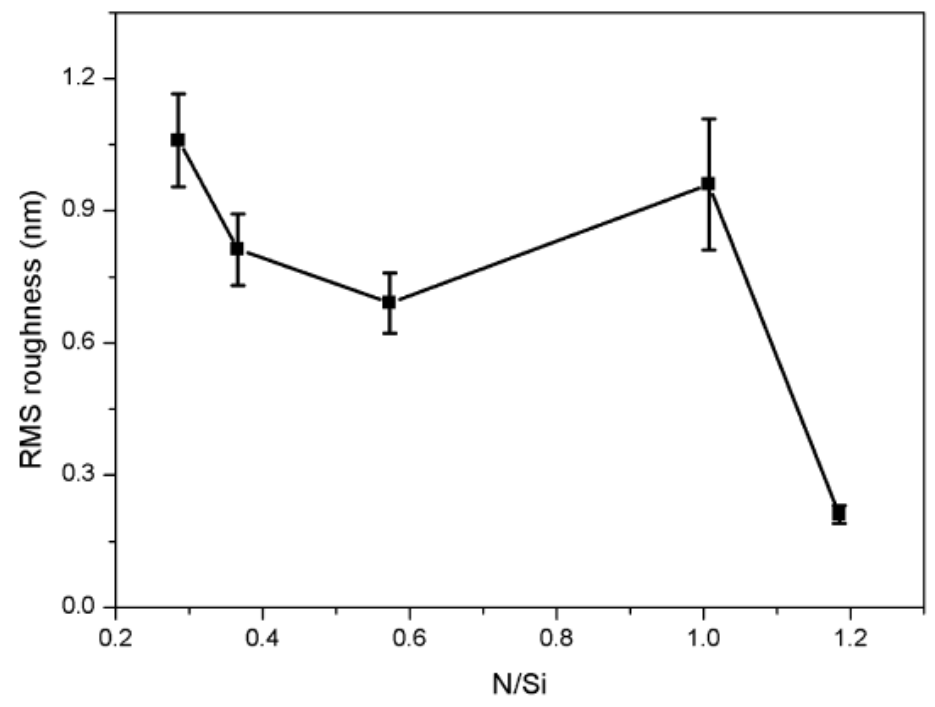

Fig. 9. RMS roughness values at various N/Si ratios. 

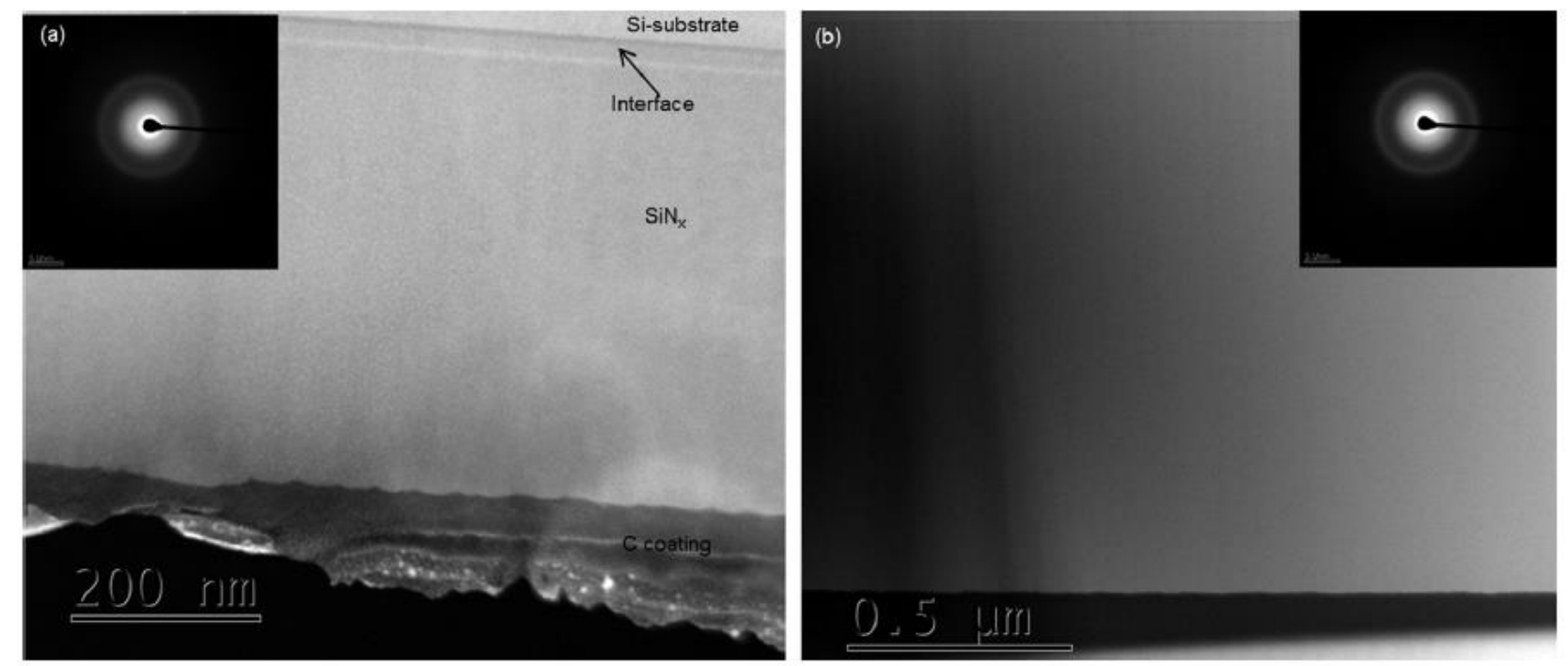

Fig. 10. TEM micrographs of the $\mathrm{SiN}_{x}$ thin films at (a) $\mathrm{N} / \mathrm{Si}=0.29$ and (b) 1.18 . The insets show diffraction patterns in each case.

Initially, $17=0.22$, is below the value of 0.25 for a-Si and above that of bulk c-Si of 0.10 [43]. Subsequently, 17 transcends the value for a-Si reaching values of $\sim 0.62$ for samples with high $\mathrm{N}$-content. Mercaldo et al. [40] observed a $17 \sim 1$ and attributed it to size-dependent enhanced electron-phonon coupling in amorphous or crystalline nanostructures within a $\mathrm{SiN} x$ thin film.

However, in this study it was not possible to directly analyze regions smaller than 4 $\mathrm{nm}$ using EELS. Additionally, the samples experienced damage after prolonged exposure to the $200 \mathrm{kV}$ electron beam. Nevertheless, the nanoscale regions of brightness in the EELS Si-maps and the simultaneous presence of $\mathrm{Si} \mathrm{Si}$ and $\mathrm{Si} \mathrm{N}$ bonds suggest that nanosized Si-rich regions may be present within the $\mathrm{SiN} x$ thin films.

Moreover, the disorder increases within the $\mathrm{Si} \mathrm{Si}$ regions as more $\mathrm{N}$ is incorporated. The cross-section of the a-Si TO Raman peak is largely determined by the deformation potential involving short-range interaction between the Si Si lattice displacement and electrons [44]. Adapting this to amorphous materials, the enhancing defects (corresponding to an increasing tensile stress) induces an enlarging displacement which reduces the TO scattering cross-section and eventually higher $I_{2} \mathrm{To} / \mathrm{ITO}$ ratios at higher $\mathrm{N} / \mathrm{Si}$ values.

Regardless of the high hydrogen dilution used in this study, no crystallization occurred as revealed by XRD, Raman spectroscopy and electron diffraction in the TEM analysis. This can be explained by the increased incorporation of nitrogen and the decrease of the $\mathrm{H}$-content as the N/Si ratio increases, which create defects within the $\operatorname{SiN} x$ thin films. Coupled with the low substrate temperature of $240{ }^{\circ} \mathrm{C}$, this impedes crystallization. The increasing number of defects results in the observed decreasing FTIR bonding densities and the observed disordering within the $\mathrm{Si} \mathrm{Si}$

\section{http://repository.uwc.ac.za}


regions as shown by Raman spectroscopy. Wanka and Schubert [45] reported on the effective etching of a native oxide film on silicon by atomic hydrogen generated by a heated filament. In line with the findings by Wanka and Schubert [45] the reduction in the oxide thickness between the $\mathrm{SiN} x / \mathrm{c}-\mathrm{Si}$ interface as the $\mathrm{NH}_{3}$ flow rate increases is attributed to an enhancing etching by atomic hydrogen.

The presence of a nitrogen-rich interface between the $\mathrm{SiN} x$ and the underlying c-Si substrate is attributed to the diffusion of $\mathrm{N}$ within the oxide layer.

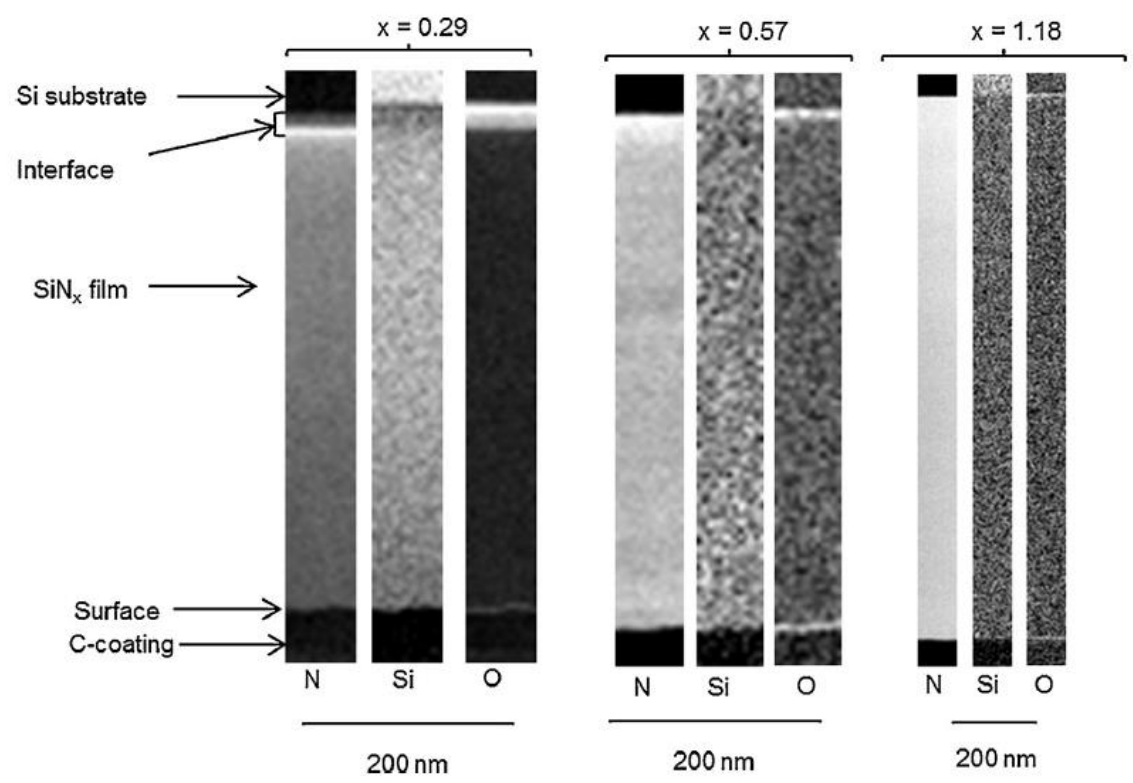

Fig. 11. Normalized EELS elemental N, Si and O maps of the $\mathrm{SiN}_{x}$ thin films with different $\mathrm{N} / \mathrm{Si}$ ratios. 


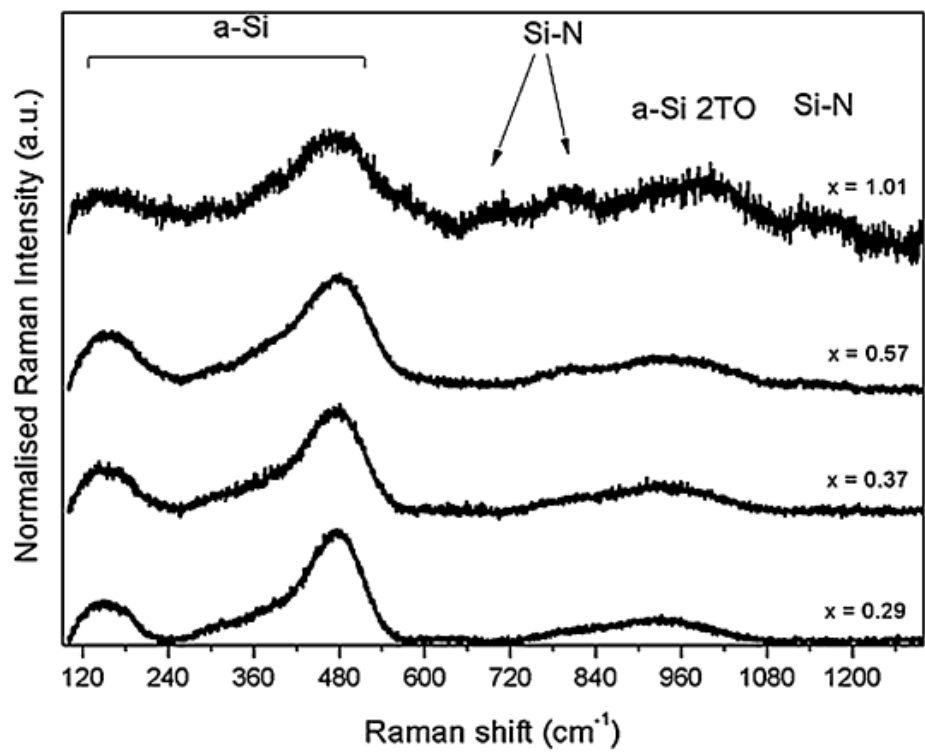

Fig. 12. Raman spectra of the $\mathrm{SiN}_{x}$ samples with varying N/Si ratios.

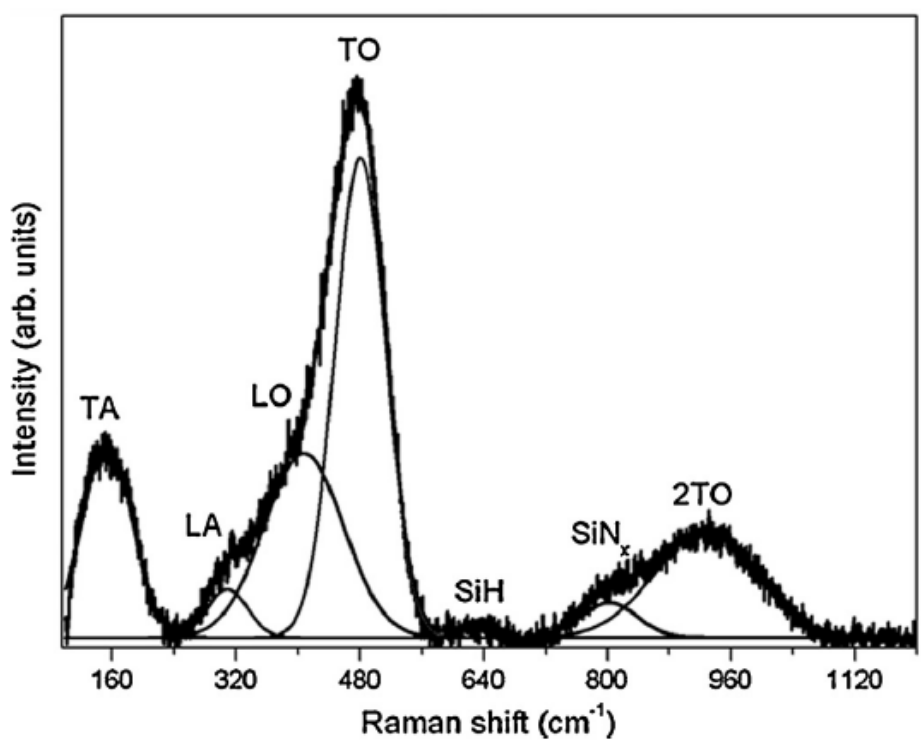

Fig. 13. Deconvoluted Raman spectrum of a $\mathrm{SiN}_{x}$ sample. The a-Si peaks labelled TO, 2TO LO, LA and TA are present with peaks for $\mathrm{SiN}_{x}$ and $\mathrm{SiH}$.

The $\mathrm{N}$ atoms then passivate the dangling bonds within the oxide by forming energetically favoured Si N bonds, resulting in a nitrogen-rich interface. Fukuda et al. [46] reported similar findings in their thermally oxynitridation studies of a $\mathrm{Si}(10 \mathrm{O})$ wafer. The reduction of the N-rich interface-thickness with an increasing $\mathrm{NH}_{3}$ flow rate is due to the reduction in the native oxide thickness owing to the enhancing etching of atomic hydrogen. Coupled to a higher $\mathrm{H}$ density, the dangling bonds within the interface are passivated by hydrogen reducing the areas where $\mathrm{N}$ can bond, subsequently resulting in a decreasing N-rich interface. The presence of defects within the $\operatorname{SiN} x$ thin films further manifest in the form of film stress. Fig. 16 shows the film stress as a function of N/Si; revealing that the film is under compresive stress for $x<0.4$ and then under tensile stress 
for $x>0.55$. Hasegawa et al. [47] also observed a change in stress from compression to tensile at $\mathrm{N} / \mathrm{Si} \sim 0.5$ and attributed it to the rearangment in the $\mathrm{Si}$ N network.

Specifically, the distance between $\mathrm{Si}$ and $\mathrm{N}$ becomes shortened within the distorted bonding arrangment leading to a contraction of the films as the $\mathrm{N}$ content increases; ultimately leading to tensile stress [47]. Additionally, the inreasing deposition rate as the $\mathrm{NH}_{3}$ flow rate enhances in this study results in a higher supply rate of radicals compared to the rate of $\mathrm{Si}, \mathrm{H}$ and $\mathrm{N}$ incorporation wihin the $\mathrm{SiN} x$ thin films consequently, resulting in the deposition of a disordered, tensile network at $\mathrm{N} / \mathrm{Si}>0.55$.

\subsection{Optical properties and film stress}

The understanding of the optical properties of $\mathrm{SiN} x$ films is vital considering that they can be applied as anti-reflective coatings on solar cells. Fig. 17 presents the dispersion in the absorption coefficient and refractive index at vaiours photon energies. The refractive index and absorption coefficient decrease with an enhancing $\mathrm{N}$ content within the films.
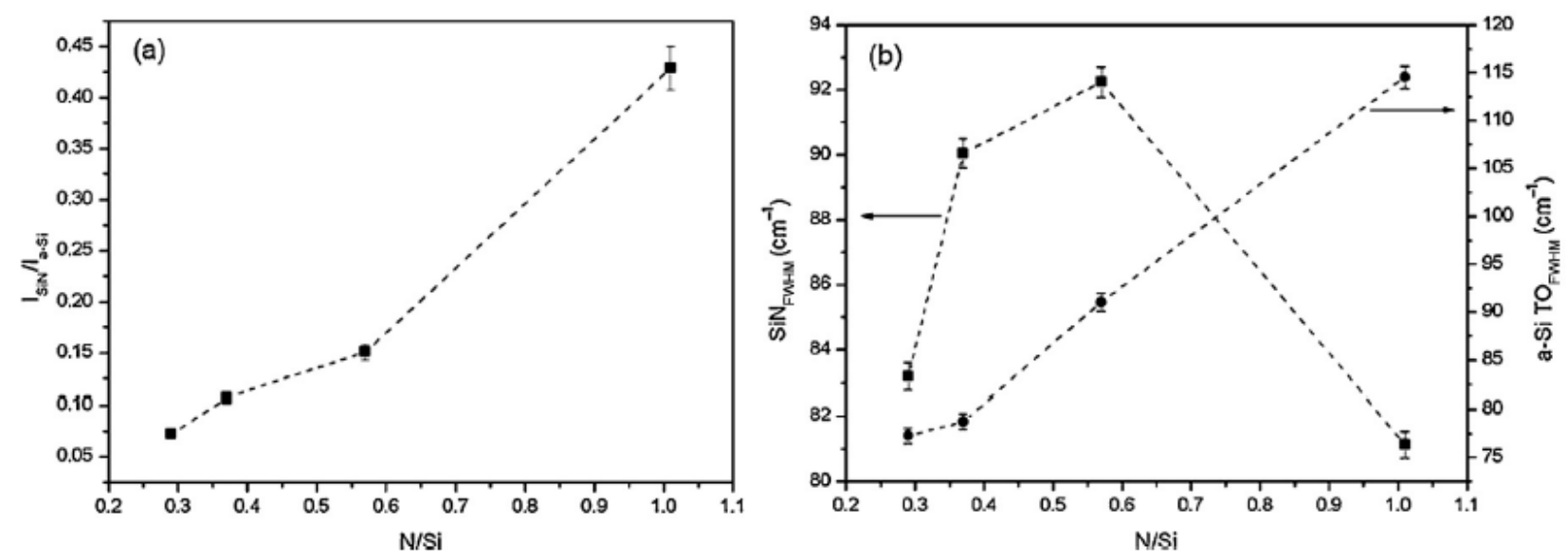

Fig. 14. (a) Intensity ratio of the a-Si TO peak to the $\mathrm{SiN}_{x}$ peak and (b) variation of the FWHM of the $\mathrm{SiN}_{x}$ and a-Si TO peaks at different N/Si ratios.

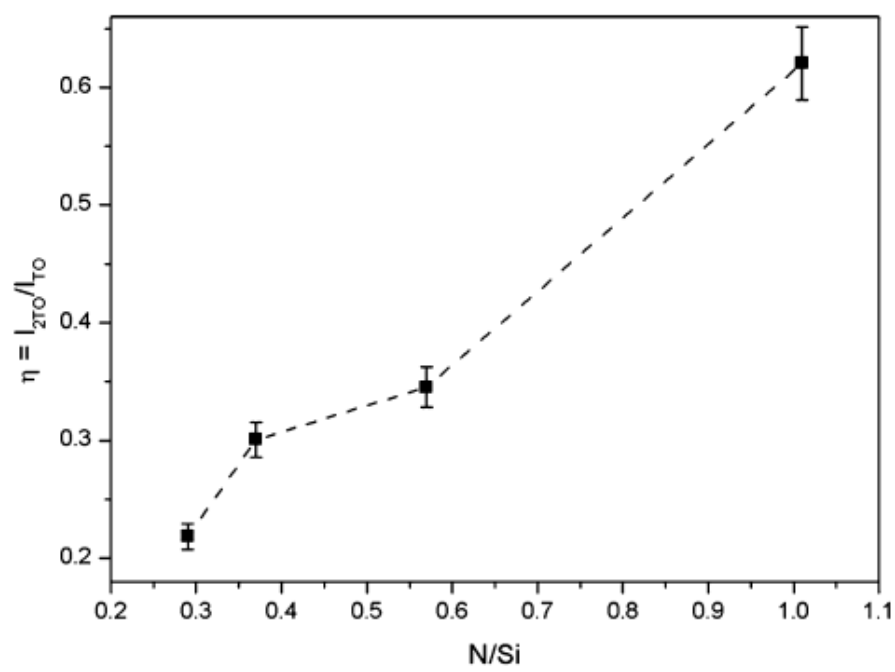

Fig. 15. Intensity ratio of second- to first-order of a-Si at various $\mathrm{N} / \mathrm{Si}$ ratios. 


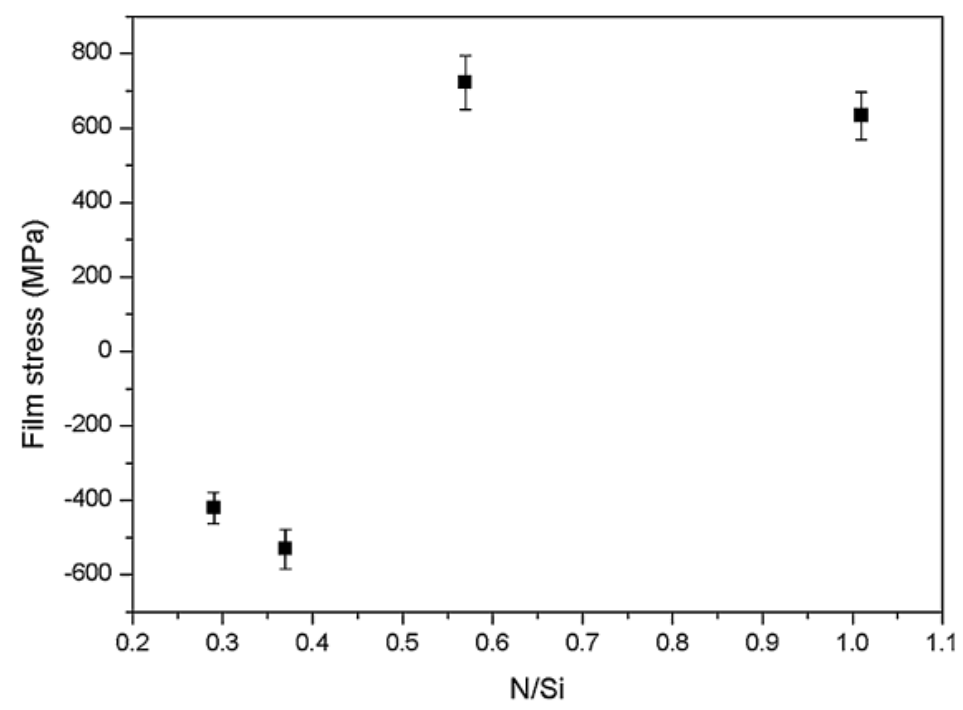

Fig. 16. Intrinsic film stress at various $\mathrm{N} / \mathrm{Si}$ ratios.

This trend is consistent with the enhancing SiN phase as observed by XPS. Fig. 18 shows the refractive index $(n)$ at $632 \mathrm{~nm}$ and the extintion coeffifcient $(k)$ at $400 \mathrm{~nm}$ of the $\operatorname{SiN} x$ thin films as a function of N/Si. The refractive index decrease linearly with an increasing N/Si ratio according to:

$$
n_{632 \mathrm{~nm}}=3.92-1.81\left(\frac{\mathrm{N}}{\mathrm{Si}}\right)
$$

The extrapolated $n 630 n m$ value of $3.92 \pm 0.21$ at $\mathrm{N} / \mathrm{Si}=\mathrm{o}$ is close to the value reported for microcrystalline silicon of 3.75 [48]. The expected value of $n 632 \mathrm{~nm}=1.51 \pm 0.24$ at $\mathrm{N} / \mathrm{Si} \sim 1.33$ is lower than the value of 1.90 for $a-\mathrm{Si}_{3} \mathrm{~N}_{4}$ and is attributed to the presence of tensile stress observed for $\operatorname{SiN} x(x>0.57)$ thin films in this study.

The enhancing incorporation of $\mathrm{N}$ within the film results in the increasing number of the energetically favoured $\mathrm{Si} \mathrm{N}$ bonds [34] and a reduction in the [Si Si] bonds. Fig. 18b shows that a noticeable reduction of $k_{400 n m}$ occurs with an increase in the N/Si ratio, which idicate less absorption within the visible wavelenght regions. Fig. 19 shows the Tauc band gap of the $\mathrm{SiN} x$ layers disclosing that the band gap widens linearly with an increase in $\mathrm{N} / \mathrm{Si}$ according to:

$$
E_{\text {Tauc }}=1.31+2.49\left(\frac{\mathrm{N}}{\mathrm{Si}}\right)
$$


The relation expressed in Eq. (7) differs from that reported for the deposition of $\operatorname{SiN} x$ from $\mathrm{SiH}_{4}$ and $\mathrm{NH}_{3}$ gas mixtures [49].

Nevertheless, the ETauc values reduces to $1.31 \mathrm{eV}$ at N/Si = o; corresponding well with the reported value for microcrystalline silicon [32] and to $4.63 \mathrm{eV}$, which is approaching $5 \mathrm{eV}$ for $\mathrm{Si}_{3} \mathrm{~N}_{4}[5 \mathrm{O}]$.

The Tauc optical band gap increased linearly with an enhancing N/Si ratio. Conversely, the refractive index decreased linearly with an increasing N/Si ratio. The behaviour of the optical properties corresponds well to the increasing $\mathrm{N}$ and $\mathrm{Si} \mathrm{N}$ concentration, regardless of the presence of $\mathrm{Si} x \mathrm{~N}_{y} \mathrm{O}_{z}$ interfaces. These interfaces are relatively low in concentration compared to the $\operatorname{SiN} x$ bulk and therefore changes within the chemical composition especially $\mathrm{N}$ incorporation into the $\mathrm{SiN}$ thin films dominate the optical properties.
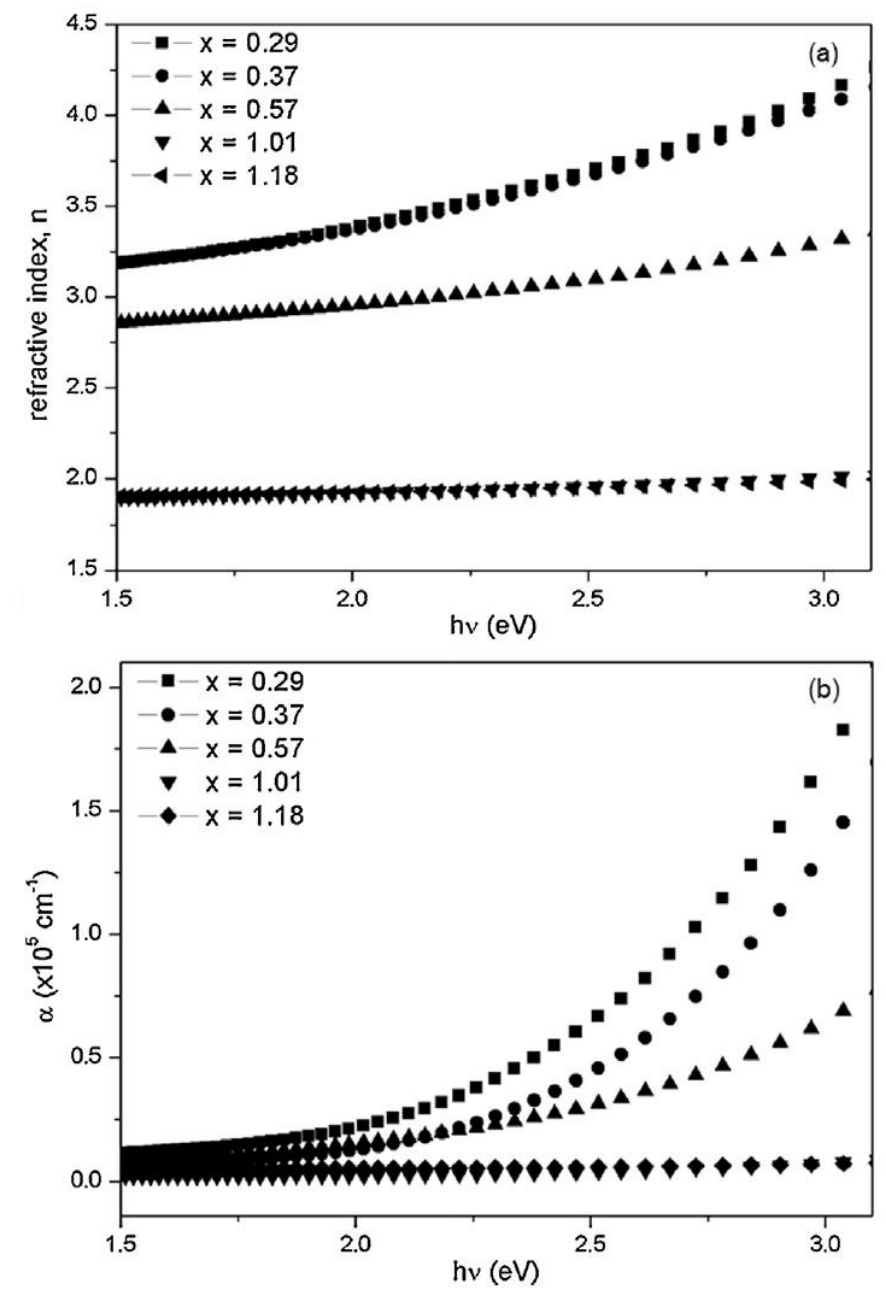

Fig. 17. Dispersion in the (a) refractive index and (b) absorption coefficient of $\mathrm{SiN}_{x}$ thin films with various $\mathrm{N} / \mathrm{Si}$ ratios. 

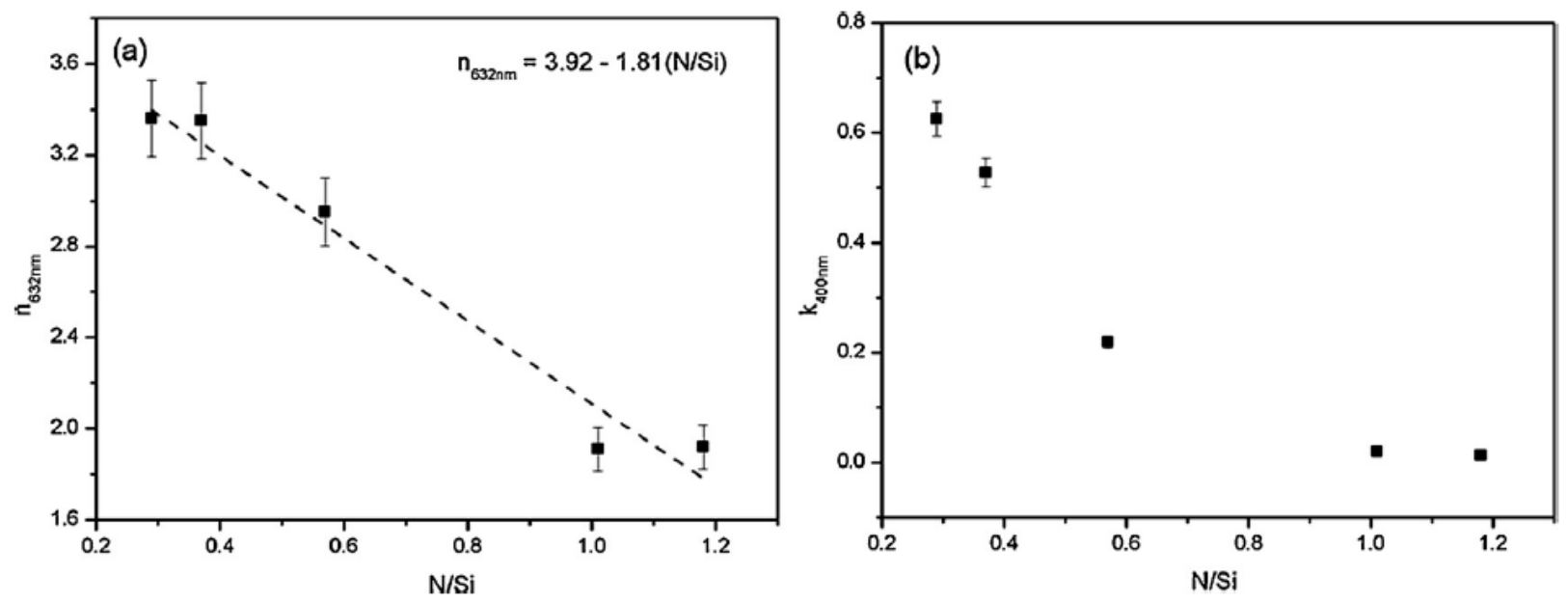

Fig. 18. (a) Refractive index at $632 \mathrm{~nm}$ and (b) extinction coefficient at $400 \mathrm{~nm}$ as a function of N/Si.

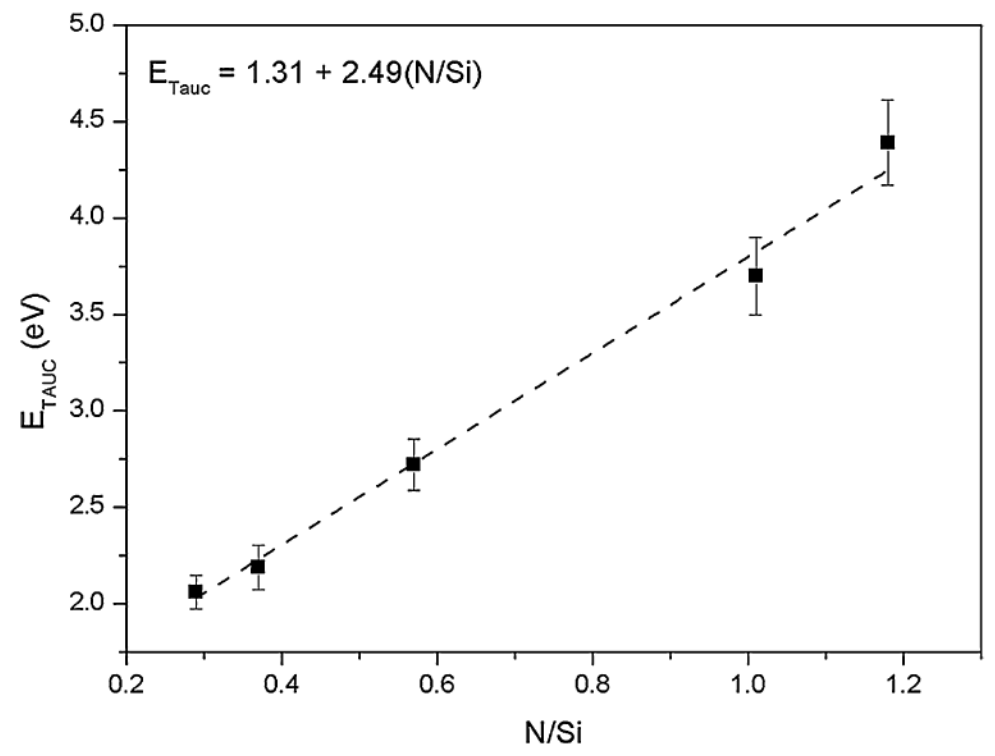

Fig. 19. Tauc optical band gap as a function of $\mathrm{N} / \mathrm{Si}$ ratio.

\section{Conclusion}

The chemical composition, bonding densities, stress and optical properties of hydrogenated $\mathrm{SiN}_{\mathrm{X}}$ thin films as a function of $\mathrm{NH}_{3}$ flow rate synthesized by HWCVD have been studied. Independent XPS and EDS analysis corroborate each other on the determination of the $\mathrm{N} / \mathrm{Si}$ ratio. Nitrogen from the $\mathrm{NH}_{3}$ gas was effectively incorporated into the film, while the hydrogen content decreased with an increasing $\mathrm{N} / \mathrm{Si}$ ratio. The band gap of the $\mathrm{SiN}_{\mathrm{X}}$ thin films increased with an enhancing N/Si ratio. Conversely, the refractive index decreased with an increasing $\mathrm{N} / \mathrm{Si}$ ratio. Compressive film stress occurred in Si-rich $\mathrm{SiN}_{\mathrm{X}}$ thin films, which decreases and then changed to tensile stress as the $\mathrm{N}$ content increase. Filament degradation and gas phase reactions determined the SiNx growth rate. The increasing incorporation of $\mathrm{N}$ within the SiNx thin films created defects, regardless of the improved etching by atomic hydrogen as the $\mathrm{NH}_{3}$ flow rate is increased. Nevertheless, highly transparent, H-containing and low reflection $\mathrm{SiN}_{\mathrm{X}}$ layers 
with smooth surfaces were deposited, which is promising for applications as antireflective coatings and passivation layers on solar cells.

\section{Acknowledgements}

The authors acknowledge the financial support of the National Research Foundation (NRF), the Department of Science and Technology (DST) and the National Metrology Institute of South Africa (Project no, TPo21). The authors are thankful to Mr. P. Greeff, National Metrology Institute of South Africa, for helping with the film stress measurements. Dr. D. Motaung, National Centre for Nanostructured Materials, is acknowledged for assistance with the XRD, FTIR and Raman measurements. 


\section{References}

[1] V. Verlaan, C.H.M. van der Werf, Z.S. Houweling, I.G. Romijn, A.W. Weeber, H.F.W. Dekkers, H.D. Goldbach, R.E.I. Schropp, Prog. Photovoltaics Res. Appl. 15 (2007) 563.

[2] B. Stannowski, J.K. Rath, R.E.I. Schropp, Thin Solid Films 395 (2001) 339.

[3] R.E.I. Schropp, C.H.M. van der Werf, V. Verlaan, J.K. Rath, H. Li, Thin Solid Films 517 (2009) 3039.

[4] N. Park, C. Choi, T. Seong, S. Park, Phys. Rev. Lett. 86 (2001) 1355.

[5] V. Verlaan, A.D. Verkerk, W.M. Arnoldbik, C.H.M. van der Werf, R. Bakker, Z.S. Houweling, I.G. Romijn, D.M. Borsa, A.W. Weeber, S.L. Luxembourg,

M. Zeman, H.F.W. Dekkers, R.E.I. Schropp, Thin Solid Films 517 (2009) 3499.

[6] F. Giorgis, F. Giuliani, C.F. Pirri, E. Tresso, C. Summonte, R. Rizzoli, R. Galloni, A. Desalvo, P. Rava, Philos. Mag. B 77 (1998) 925.

[7] V. Verlaan, Z.S. Houweling, C.H.M. van der Werf, I.G. Romijn, A.W. Weeber, H.D. Goldbach, R.E.I. Schropp, Thin Solid Films 516 (2008) 533.

[8] A. Masuda, H. Umemoto, H. Matsumara, Thin Solid Films 501 (2006) 149.

[9] A.H. Mahan, A.C. Dillon, L.M. Gedvilas, D.L. Williamson, J.D. Perkins, J. Appl. Phys. 94 (2003) 2360.

[10] F. Liu, S. Ward, L. Gedvilas, B. Keyes, B. To, Q. Wang, E. Sanchez, S. Wang, J. Appl. Phys. 96 (2004) 2973.

[11] Q. Wang, S. Ward, L. Gedvilas, B. Keyes, E. Sanchez, S. Wang, Appl. Phys. Lett. 84 (2004) 338.

[12] P. Alpuim, L.M. Gonc, alves, E.S. Marins, T.M.R. Viseu, S. Ferdov, J.E. Bourée, Thin Solid Films 517 (2009) 3503.

[13] J.E. Bourée, J. Guillet, C. Grattepain, J. Chaumont, Thin Solid Films 430 (2003) 110.

[14] C.J. Arendse, D. Knoesen, D.T. Britton, Thin Solid Films 501 (2006) 92.

[15] N. Maley, Phys. Rev. B 46 (1992) 2078.

[16] M.H. Brodsky, M. Cardona, J.J. Cuomo, Phys. Rev. B 16 (1977) 3556.

[17] G.G. Stoney, Proc. R. Soc. London A 82 (1909) 172.

[18] K. Takimoto, A. Fukuta, Y. Yamamoto, N. Yoshida, T. Itoh, S. Nonomura, J. Non-Cryst. Solids 299-302 (2002) 314.

[19] T.F.G. Muller, C.J. Arendse, S. Halindintwali, D. Knoesen, R.E.I. Schropp, Thin Solid Films 519 (2011) 4462.

[20] A. Kshirsagar, P. Nyaupane, D. Bodas, S.P. Gangal, Appl. Surf. Sci. 257 (2011) 5052.

[21] E. Zeiler, S. Schwarz, S.M. Rosiwal, R.F. Singer, Mater. Sci. Eng. A-Struct. A335 (2002) 236.

[22] C.H.M. van der Werf, P.A.T.T. van Veenendaal, M.K. van Veen, A.J. Hardeman, M.Y.S. Rusche, J.K. Rath, R.E.I. Schropp, Thin Solid Films 430 (2003) 46.

[23] I. Langmuir, J. Am. Chem. Soc. 34 (1912) 860. 
[24] A. Gallagher, Thin Solid Films 395 (2001) 25.

[25] E. Bustarret, M. Bensouda, M.C. Habrard, J.C. Bruyère, S. Poulin, S.C. Gujrathi, Phys. Rev. B 38 (1988) 8171.

[26] V. Verlaan, C.H.M. van der Werf, W.M. Arnoldbik, H.D. Goldbach, R.E.I. Schropp, Phys. Rev. B 73 (2006) 195333.

[27] H. Matsumura, A. Masuda, H. Umemoto, Thin Solid Films 501 (2006) 58.

[28] W.A. Lanford, M.J. Rand, J. Appl. Phys. 49 (1978) 2473.

[29] Z. Yin, F.W. Smith, Phys. Rev. B 42 (1990) 3666.

[30] J.J. Mei, H. Chen, W.Z. Shen, H.F. Dekkers, J. Appl. Phys. 100 (2006) 073516. [31] C.J. Oliphant, C.J. Arendse, D. Knoesen, T.F.G. Muller, S. Prins, G. Malgas, Thin Solid Films 519 (2011) 4437.

[32] R.E.I. Schropp, M. Zeman, Amorphous and Microcrystalline Silicon Solar Cells: Modelling, Materials and Device Technology, Kluwer Academic, Boston, 1998.

[33] A.K. Panchal, C.S. Solanki, J. Cryst. Growth 311 (2009) 2659.

[34] F.W. Smith, Z. Yin, J. Non-Cryst. Solids 137-138 (1991) 871.

[35] Verlaan, Z.S. Houweling, C.H.M. van der Werf, H.D. Goldbach, R.E.I. Schropp, MRS Proc. 910 (2006), 0910-A03-03.

[36] B. Stannowski, J.K. Rath, R.E.I. Schropp, J. Appl. Phys. 93 (2003) 2618.

[37] R.E.I. Schropp, S. Nishizaki, Z.S. Houweling, V. Verlaan, C.H.M. van der Werf, H. Matsumura, Solid State Electron. 52 (2008) 427.

[38] H. Umemoto, T. Morimoto, M. Yamawaki, Y. Masuda, A. Masuda, H. Matsumura, Thin Solid Films 430 (2003) 24.

[39] M.S. Valipa, T. Bakos, E.S. Aydil, D. Maroudas, Phys. Rev. Lett. 95 (2005) 216102.

[40] L.V. Mercaldo, E.M. Esposito, P.D. Veneri, G. Fameli, S. Mirabella, G. Nicotra, Appl. Phys. Lett. 97 (2010) 153112.

[41] J. Bandet, B. Despax, M. Caumont, J. Appl. Phys. 85 (1999) 7899.

[42] M. Luysberg, P. Hapke, R. Carius, F. Finger, Philos. Mag. A 75 (1997) 31. [43] P. Mishra, K.P. Jain, Phys. Rev. B 64 (2001) 073304.

[44] R.P. Wang, G. Xu, P. Jin, Phys. Rev. B 63 (2004) 113303.

[45] H.N. Wanka, M.B. Schubert, MRS Proc. 467 (1997) 651.

[46] H. Fukuda, M. Yasuda, T. Iwabuchi, S. Ohno, Appl. Surf. Sci. 6o/61 (1992) 359.

[47] S. Hasegawa, Y. Amano, T. Inokuma, Y. Kurata, J. Appl. Phys. 72 (1992) 5676.

[48] A. Fontcuberta i Morral, P. Roca i Cabarrocas, Thin Solid Films 383 (2001) 161.

[49] B. Swatowska, T. Stapinski, Vacuum 82 (2008) 942.

[50] I.V. Afanasyev-Charkin, M. Nastasi, Nucl. Instrum. Methods B 206 (2003) 736. 